\title{
JOSÉ TAMAYO: LA BÚSQUEDA DESDE EL EXTERIOR DE UNA ESTÉTICA INNOVADORA PARA LA ESCENA ESPAÑOLA DE POSGUERRA (1949-1951)
}

\author{
Juan Miguel Tévar Angulo \\ juantevar@hotmail.es
}

\section{RESUMEN}

Entre los años 1949-1951 José Tamayo con su Compañía Lope de Vega emprende una gira por siete países americanos. Durante su estancia en América mantiene relación con los exiliados españoles y en especial con el Catedrático de Ciencias Sociales de la Universidad de Rio Piedras, en San Juan (Puerto Rico), Alfredo Matilla Jimeno, antiguo militante de Izquierda Republicana. Durante el periplo americano se configura una buena parte de la estética teatral de José Tamayo, que a su regreso a España estrena La muerte de un viajante de Arthur Miller. El dramaturgo norteamericano concede los derechos de representación para España por la influencia y credibilidad de los amigos del Catedrático.

Palabras Clave: Arthur Miller. José Tamayo. La muerte de un viajante.

\section{SUMMARY}

Between the years 1949-1951 José Tamayo with his Company Lope de Vega takes a tour of seven South American countries. During his stay in America maintains relationship with the Spanish exiles and especially with the Professor of Sciences Social of the University of Rio Piedras, San Juan (Puerto Rico), Alfredo Matilla Jimeno, former 
member of Republican left. The American journey is set to a large part of the theatrical aesthetics of José Tamayo, who on his return to Spain opens The death of a salesman by Arthur Miller. The American playwright grants representation rights for Spain by the influence and credibility of the friends of the professor.

KEY WORDS: Arthur Miller. José Tamayo. La muerte de un viajante.

En los últimos meses del año 2002 José Tamayo acudía a la Universidad de Murcia invitado por su amigo César Oliva, para hablar del montaje de La muerte de un viajante estrenado por el director y empresario, en el Teatro de la Comedia de Madrid, el 10 de enero de 1952. El reencuentro con el catedrático, la universidad y Miller configuraron el último acto académico de José Tamayo.

Lo citado en estas líneas va más allá de la simple anécdota histórica en la vida de este hombre de teatro, puesto que a la pregunta de qué le impulsó a traer a España el título de Miller, contestó: el problema humanísimo. Así lo atestiguó su secretario Alberto Guereca, y así lo podría corroborar el propio César Oliva. Es evidente que el subtexto de carácter marxista no invitó al director a su puesta en escena en el momento de su estreno, ni cincuenta años después. Tampoco antes, cuando desde Barranquilla (Colombia) escribió a fecha 4 de abril de 1951 a su amigo Alfredo Matilla Jimeno: Vi en Bogotá, representada por una Compañía Argentina que acaba de debutar, la obra de Arthur Miller, La muerte de un viajante. Es algo maravilloso, de una humanidad y un interés impresionante. (Tamayo, 1951: Carta a Matilla Jimeno, A.)

En septiembre de 1949 José Tamayo emprendía con escasos medios económicos una gira por siete países de América (Cuba, Puerto Rico, República Dominicana Venezuela, Colombia, Panamá y Costa Rica). Nada de nuevo tenía que una compañía teatral visitara países de habla hispana, ya se había hecho en numerosas ocasiones. Lo diferencial estribó en los factores humanos y artísticos que se conjugaron durante el recorrido de la Compañía Lope de Vega por tierras americanas, y la repercusión posterior en el panorama teatral español. De los motivos que impulsaron a José Tamayo a esta experiencia únicamente podemos establecer hipótesis, que nos conducen a dos posibles respuestas.

La supervivencia de una compañía teatral que provenía de Granada, del Teatro Universitario Lope de Vega, profesionalizada el 10 de octubre de 1946 -fecha en la que se presenta en el Teatro Eslava de Valencia con la obra de Shakespeare Romeo y Julieta-, con un repertorio basado en los clásicos y los autos sacramentales tenía seriamente comprometida su continuidad en los circuitos profesionales del teatro. Económicamente insostenible. En el plano artístico un estancamiento noble dentro de lo ya sabido. Cierto que la Compañía Lope de Vega también llevaba a Cocteau, Thornton Wilder, y obras de autores consagrados por el favor de un público con ideología restauradora. Puso en escena a algunos noveles. Entre estos últimos José Martín Recuerda, Dauro. Pero durante el periodo 1946 a 1949 el prestigio de la Compañía Lope de Vega no alcanza más allá que al reconocimiento de la crítica, apoyando la iniciativa de un joven director teatral que se atreve a recorrer España con un repertorio difícil e inhabitual en la empresa privada, 
aunque apoyado por una cabecera de cartel solvente. La Compañía Lope de Vega nace con el propósito de dar réplica de disconformidad a la lamentable situación del teatro español de posguerra. En 1944 José Tamayo denunciaba, desde la revista Cuadernos de Teatro, la pobreza ideológica y estética de la escena española:

Poco se puede esperar de las compañías profesionales que, con sus viejos trastos, hoy ruedan por los escenarios de provincias, con un teatro detestable, con unas formaciones de intereses, faltas de técnica teatral y en manos de unos empresarios que debieran dedicarse a otros negocios. ¡Esto es la negación del teatro! (Tamayo, 1944: s/p).

El segundo motivo, derivado del primero, ir al encuentro de una estética imposible desde el interior. España era un país cerrado. Con una urgente necesidad de renovación teatral a todos los niveles, pero sujeto a la férrea estructura del aparato cultural franquista.

Este lenguaje culto, heredado de Antonio Gallego y Burín, es el que lleva a América. La estética teatral española de 1949 con sus representantes de mayor calidad. El repertorio incluía autores de éxito entre los que sobresalían Joaquín Calvo Sotelo, Jacinto Benavente, Juan Ignacio Luca de Tena y José López Rubio. Los clásicos: Zorrilla, Lope, Calderón, Shakespeare con un impresionante Otelo, y una versión de Hamlet realizada por José María Pemán, de recepción pésima por los críticos de los países americanos. Los hermanos Álvarez Quintero, Ángel Guimerá. Dickens, El anticuario, en versión de Suárez de Deza -igualmente recibido con reparos por la función crítica-. Representó dos obras de autores americanos de habla hispana, sin éxito. Y supo unir el nombre de la Compañía Lope de Vega a los de Antonio Buero Vallejo y Alejandro Casona. Hipólito Hidalgo de Caviedes y Fernando Botero, con sus escenografías.

Dos años estuvo de gira la Compañía Lope de Vega por América y durante ese espacio de tiempo se conformó buena parte de la estética teatral de José Tamayo. La búsqueda, la relación con los exiliados españoles y la entrega absoluta a su profesión -la mantuvo hasta el final-, dieron por resultado una aportación innovadora a la escena española, que se inicia a su regreso con el estreno de La muerte de un viajante.

En enero de 1949 José Tamayo viajó al continente americano con la intención de cerrar los primeros contratos para la gira que ya pensaba realizar. Por indicación de un amigo español -del que nunca quiso desvelar el nombre-, se puso en contacto, a su llegada a San Juan de Puerto Rico, con el Catedrático de Ciencias Sociales de la Universidad de Rio Piedras, español exiliado y antiguo militante de Izquierda Republicana, Alfredo Matilla Jimeno. Habría de ser un hombre de enorme influencia en el joven artista. En aquel momento era el director de Actividades Socio Culturales de la Universidad. Si bien al principio recibió a Tamayo con recelo, después surgió una amistad que se extendió a lo largo de muchos años. Por otro lado, Alfredo Matilla Jimeno tenía relación con Francisco García Lorca, hermano de Federico y profesor de la Universidad de Columbia en Nueva York. Y por aportar otro dato era amigo personal de Alejandro Casona y Cipriano de Rivas Cherif, cuyos hijos estudiaban en la Universidad de Rio Piedras. Estos fueron, entre otros de gran prestigio, los contactos que José Tamayo mantuvo con los exiliados españoles durante la gira americana. Es aquí donde debemos encontrar las claves del lenguaje dramático que el director introduce en el panorama teatral español. Un lenguaje cercano a la izquierda, sin que por ello se perfilara. Manteniendo siempre una postura ambigua entre un teatro conservador y un teatro progresista. También es muy revelador de la idiosincrasia de José 
Tamayo su mirada onírica de la vida real -sirvió de anagrama al estandarte de su Compañía Lope de Vega, Camina mejor quien va mirando a las estrellas. Sobre todo el corazón-, que le lleva durante su estancia en América, además de estrenar a Casona e intentar rescatar a Federico García Lorca con La zapatera prodigiosa, pensar en contratar para España a María Casares, junto al propósito de hacer una gira por los Estados Unidos y sus universidades. Pero si todo esto, que, en sí, encierra un gran valor, no fuera suficiente, produjo y dirigió a su regreso a España el estreno de La muerte de un viajante. Justo es decir que con la inestimable ayuda de los exiliados. Todo el periplo americano de la Compañía Lope de Vega estuvo sujeto a dos formas de pensamiento antagónico y sin posible reconciliación en aquellos momentos. El de los exiliados y el de la España oficial, con la que mantiene contactos y, en realidad, le fue abriendo las puertas a las contrataciones en los distintos países que visitó. Dos formas sincronizadas y hasta «jugadas» desde un tercer pensamiento: el de José Tamayo. Manteniendo un ejercicio de equilibrio que le permitió el apoyo y captación de los intelectuales españoles exiliados, y el posterior regreso a España sin dificultades, en el complejo espectro político de nuestro país en 1951.

Durante años, y aún hoy, los intelectuales y estudiosos del teatro se han preguntado cómo Miller autorizó el estreno en España de La muerte de un viajante. Trataremos de arrojar un poco de luz a esta cuestión, y sobre el mito del posible calco del montaje de José Tamayo de la producción de Broadway. También abordaremos otros aspectos de la gira americana, de una manera extractada, dado que este artículo corresponde a una tesis doctoral, que hemos defendido bajo la dirección del Catedrático don Francisco Gutiérrez Carbajo.

Tal y como hemos dicho el director y empresario viajó a diversos países americanos en 1949, incluido Estados Unidos, entre los meses de enero y marzo por espacio de 40 días, guiándonos por sus declaraciones a Gómez Ramos para el periódico Pueblo. (Tamayo, 1962: 26-Pueblo) La obra de Miller se estrenó en el Teatro Morosco de Nueva York el día 10 de febrero de 1949. No era la primera visita de José Tamayo a la ciudad de los rascacielos, ya había estado en 1947. En ese primer viaje asistió a una representación de Un tranvía llamado deseo de Tennessee Williams dirigida por Elia Kazan, y protagonizada por Marlon Brando, Jessica Tandy y Karl Malden. A su regreso a España parece que inició alguna gestión para el estreno en Madrid -el dato es impreciso, y afectado por la memoria de transmisión verbal-, pero los imperativos de la censura fueron tan férreos que aconsejaron desistir del empeño. En 1993 retomó el proyecto con irregular resultado de público y crítica. Es de lógica pensar que si en 1949, en los días de estancia en Nueva York, hubiera visto la obra de Miller, de inmediato se hubiese puesto a negociar su estreno en Madrid, como hizo posteriormente. Otro dato que hay que tener en cuenta es el hecho de que pasara por Nueva York en el mes de enero o los primeros días de febrero, cuando aún no se había estrenado el texto de Miller. Ni un solo documento acredita que José Tamayo viera el montaje neoyorkino. Sin embargo aportamos pruebas del encuentro con el texto de Miller en Bogotá, y de que inmediatamente escribió a Alfredo Matilla Jimeno, no sólo para comunicarle el impacto que le produjo la representación -ya lo hemos visto-, sino también para solicitar su ayuda:

[...] He escrito al traductor, un tal Manuel Barberá, español, domiciliado en Argentina, en solicitud de la exclusiva para España. Sería una novedad interesante para mi presentación 
en Madrid. Este hombre me dice que se dirige a Arthur Miller en busca de ella. Si surge alguna dificultad, ¿tienes en EE.UU. alguna persona que pueda ver a este hombre, le hable de nosotros, de mis proyectos de hacerla en España con los máximos honores, y, en fin, de persuadirle para que nos de los derechos de representación.? (Tamayo, 1951: Carta a Matilla Jimeno, A.)

Nada más ver la representación realizada por la Compañía Argentina de Francisco Petrone, que estrenó el título de Miller con el nombre de La muerte de un vendedor, se puso en contacto por carta con el traductor de la obra Manuel Barberá, hombre que contaba con una dilatada experiencia en la traducción de textos de teatro. Como desconocía la dirección de este señor se dirigió a él a través de la Sociedad Argentina de Autores. Es evidente que actuó con gran discreción al utilizar un conducto seguro al margen de la Compañía Petrone. José Tamayo por carta de 7 marzo de 1951 informó a Barberá de que estaba interesado en la obra de Arthur Miller, teniendo encomendado a un amigo suyo de Nueva York este tema, pero que al ver la representación de Bogotá había pensado que la versión castellana traducida por él pudiera ser válida para España. Añadiendo que hiciera lo posible por comunicarse con Miller con el fin de obtener los derechos de representación para nuestro país. En caso de obtener la licencia de exhibición tomaría las medidas necesarias para que el estreno fuera reservado a la Compañía con exclusividad absoluta, incluso de cara a los Teatros de Cámara. (Tamayo, 1951: Carta a Barberá, M.) Resulta evidente que, de una manera sutil, José Tamayo en realidad lo que estaba haciendo era un tanteo a Arthur Miller a través de Barberá. No existía el tal amigo en Nueva York. O mejor dicho, el amigo existió después y fue Alfredo Matilla Jimeno, que tampoco logró entrevistarse con Miller. Hasta donde han llegado nuestras investigaciones no hemos podido encontrar respuesta al hecho de que posteriormente descartara la traducción de Barberá.

A finales de octubre de 1950 cuando la Ley Mac Carran entró en vigor en Estados Unidos los funcionarios decidieron no conceder visados de entrada hasta no recibir instrucciones precisas. Esta ley se aprobó con el voto en contra del Presidente, y entraba en contradicción con los intereses norteamericanos en España, dado que en ese momento los gobiernos de ambos países gestionaban la instalación de las bases USA en nuestro territorio. José Tamayo por esas fechas tenía previsto un viaje a Nueva York con Alfredo Matilla. El objetivo del viaje era entrevistarse con todos los españoles relacionados con el mundo de la universidad y la cultura- Federico Onís, Pedro Salinas, Francisco García Lorca, en este caso para intentar obtener los derechos de representación de La zapatera prodigiosa-, y captar los apoyos necesarios para una posible gira de la Compañía Lope de Vega por las universidades de ese país. Otro motivo era conseguir una entrevista personal con Arthur Miller. Por último pensaba ver todo el teatro neoyorkino de interés con la intención de incorporar lo mejor de su cartelera a España. El viaje al final sólo lo pudo realizar Alfredo Matilla al no llegarle a José Tamayo el visado de entrada a tiempo. Era preciso hacer declaración jurada de no haber pertenecido a Falange, no ser comunista, nazi, fascista y no querer ejercer una actividad política en los Estados Unidos. José Tamayo le afirmó a su amigo no haber pertenecido a Falange Española -en realidad empieza en el Teatro de Campamento de Falange Española-, añadiendo por carta escrita desde Bogotá a 26 de octubre de 1950 lo siguiente: Yo no estoy en Falange, nunca he 
sido afiliado ni he tenido carnet, y eso de milagro pues ya sabrás que en cualquier organismo, en cualquier oposición o trámite que hubiera de darse en España lo fundamental era ser del partido. No obstante, que yo sepa, estoy libre de tal cosa. (Tamayo, 1950: Carta a Matilla Jimeno, A.)

La primera gestión de Alfredo Matilla a su llegada a Nueva York fue entrevistarse con Federico Onís y Francisco García Lorca, que impartían clases en la University Columbia, con el fin de tantear las posibilidades de actuación de la Compañía Lope de Vega en las universidades norteamericanas. Desde el primer momento le argumentan la imposibilidad de realización de éste proyecto basándose en la movilización militar que se había producido en el país a consecuencia del inminente peligro de guerra con Corea, que dejó reducido a menos de la mitad el número de alumnos matriculados en las universidades. El clima prebélico redujo los presupuestos universitarios hasta el punto de llevar al cese a un veinte por ciento del profesorado no fijo. Las universidades tampoco contaban con una sección de actividades culturales; menos todavía en los que se impartía el español. Los espectáculos los creaban los propios estudiantes, y la universidad que mayor número de estudiante de español pudiera tener no pasaba de cuatrocientos. Existía otro riesgo, el de que contrataran y no llegaran a pagar. Como exponente de la situación García Lorca y Onís le comentaron a Alfredo Matilla que Pedro Salinas y Juan Ramón Jiménez tan solo percibieron por dar unas conferencias la cantidad de $\$ 50$. La carta enviada a José Tamayo desde Nueva York aporta otros datos de gran calado:

Fracasado en New York, fui, el fin de semana, a Washington a la Universidad de allá y a la Católica. En la primera apenas me oyeron; en la segunda me oyeron pero, ni con mis amigos presentes, dieron la más mínima esperanza. Fui a Princeton a hablar con Llorens (Vicente) y con Américo Castro. No querían creer que hablaba en serio del plan y al demostrarles mi interés personal todavía fueron más pesimistas que los de New York. Llorens me llevó hasta el Rector, amabilísimo que me enseño incluso el presupuesto total para demostrarme que no podían hacer nada. Fui a Baltimore, a la Universidad de John Hopkins y Salinas (don Pedro) me recibió en idénticas circunstancias. Todos encantados con el plan pero lamentado no poder llevarlo a cabo. Renuncié al viaje a Boston y llamé a Antonio Regalado a Harvard. Menos entusiasmo aún. Y he llamado a Yale, por consejo de García Lorca. El mismo hizo la llamada y habló por mí con el americano que lleva esos asuntos de español y negó toda posibilidad. (Matilla Jimeno, 1951: Carta a Tamayo, J.)

De entre la amplia correspondencia a la que se hace referencia en La muerte de un viajante y su largo y difícil proceso de contratación aportamos el contenido de unas cartas que podrían dar luz sobre la tramitación de los derechos de autor a favor de José Tamayo. El 6 de junio de 1951, Alfredo Matilla se dirige por carta a José Tamayo, aconsejándole que se ponga en contacto con el actor portorriqueño José Ferrer, al que conoció durante la estancia de la Compañía Lope de Vega en Puerto Rico. (Matilla Jimeno, 1951: Carta a Tamayo, J.) Al mismo tiempo Consuelo Vázquez, íntima amiga de Alfredo Matilla, por indicación de éste, viaja desde Puerto Rico a Nueva York con un dossier de la Compañía Lope de Vega para el Representante de la Sociedad General de Autores de España Mr. Frederick Reiter, con la intención de que se lo haga llegar a Miller, o en su defecto a sus agentes de MCA. (Tamayo, 1951: Carta a Reiter, F.) Pero la posible clave de cómo consiguió la autorización de Arthur Miller la encontramos en una carta envida a Guillermo de Reyna, Secretario General de Cinematografía y Teatro, con fecha de 
10 de junio de 1951 en San José de Costa Rica, a diez días de terminar la gira. El texto presenta de un lado la impregnación del sistema americano en el director y empresario, y de otro lado la inmensa seguridad que había adquirido; la línea que ya está dispuesto a seguir, con ayudas, o sin ellas, pero con una meta trazada. En cierta manera es una carta desafiante a la política teatral impuesta por el sistema franquista. El estreno de La mиerte de un viajante fue una producción absolutamente privada, y asumió todos los riesgos empresariales, en un país en el que el teatro de evasión invadía la cartelera, y en lucha contra unos empresarios de local -los propietarios del teatro-, sin más ambición y norte que el de la mera explotación mercantilista. Claro está que a medida que José Tamayo se fue integrando en el sistema también participó de los beneficios de ese organigrama teatral, aunque con una inversión de los valores al uso, como se expone en el $\mathrm{N}^{\mathrm{o}} 5$ de la Revista de Teatro (1953): El papel del viejo empresario de compañía hay que sustituirlo, a mi entender, por un nuevo director, que, movido por su vocación se sienta administrador de los bienes que produzca el teatro, en vez de hacerlo en un sentido de explotación. (Tamayo, 1953: 33-38) En 1951 no tenía mayor defensa que la de su propio trabajo y esfuerzo. No sin apoyos, pero si con independencia. En esta carta dirigida a Guillermo de Reyna encontramos los contactos que le llevaron a ganarse la confianza y respetabilidad de Miller y sus agentes:

[...] yo marcharé a los EE.UU., porque voy a permanecer en Nueva York, y otras ciudades durante un mes. Tengo entrevistas preparadas con Arthur Miller, con Piscator y uno de sus mejores colaboradores, el Dr. Colin, amigo nuestro. También con José Ferrer, al que conocí personalmente en Puerto Rico, y que me va a servir de introductor en el ámbito teatral neoyorkino [...] (Tamayo, 1951: Carta a Reyna de, G.)

José Tamayo nunca llegó a entrevistarse con Miller, pero lo hizo con los demás. En 1985, durante una estancia en Miami de la Compañía Amadeo Vives, por mediación de un alto ejecutivo de la compañía, ofreció a José Ferrer hacer el protagonista de La muerte de un viajante. Quizá, de alguna forma, era una asignatura pendiente desde 1951. El insigne actor no aceptó por problemas de edad, aunque confesó que siempre había sido uno de sus sueños profesionales hacer teatro en España. El título de Miller fue repuesto en ese mismo año en su Teatro Bellas Artes de Madrid, protagonizado por José Luis López Vázquez.

Los problemas para el estreno de este texto no terminaron ahí. Seguían existiendo otros factores de índole económica, que sí fueron solucionados, y el más grave de todos que resultó ser la traducción. Por qué José Tamayo optó por José López Rubio implica una difícil respuesta. Lo más probable es que lo hiciera por su conocimiento del inglés y su estancia en Hollywood. Tal vez, simplemente, por no interesar a otros autores teatrales, o por no dominar estos el idioma inglés. Pero tuvo problemas de todo tipo con la elección. El primero se le plantó a la hora de formalizar contrato con López Rubio.

El 25 de octubre de 1951, Reiter y la MCA no habían recibido la traducción del texto. Su silencio ante los norteamericanos provoca que le den un ultimátum; o se define, o aceptan otras propuestas. (Reither, 1951: Carta Tamayo, J.) ¿Por qué este silencio? Porque José López Rubio le estaba exigiendo unas condiciones deplorables, que, a su vez, José Tamayo no se atrevía a plantear a los norteamericanos. Es más, en una carta sin fechar, sin duda posterior a la del de 25 de octubre, enviada a Reiter, afirmaba que 
un dramaturgo español de gran prestigio, José López Rubio, se estaba encargando de la traducción y que en pocas fechas, aseguraba diez días, recibirían el texto traducido. No era más que una forma de ganar tiempo. El 5 de noviembre de 1951, José Tamayo se dirigió por carta a Reiter solicitando que el contrato se extendiera a nombre de José López Rubio, autor de la traducción, y en las condiciones pactadas con él, asegurando que entre ese señor y él se firmaría un contrato de exclusividad de la obra para trabajar en España. (Tamayo, 1951: Carta a Reiter, F.) La causa del retraso quedaba al descubierto: las pretensiones de José López Rubio que no se conformaba con el derecho de autor -como traductor-, que le hubiera podido corresponder, sino, que, también, pretendía apropiarse de la obra y poner al empresario de compañía a su entera disposición. Esa era la mentalidad de 1951. Muy cerca estuvo José Tamayo de aceptar irremediablemente esta medida, a no ser porque la solución al conflicto le vino impuesta por los norteamericanos. De una forma clara, educada y precisa Reiter le contesta que al abogado no le gustaba esa solución, que la cesión de licencia de explotación para España se debía al prestigio de su persona como director de la Compañía Lope de Vega y que por eso habían entrado en negociaciones. A José López Rubio no lo conocían, no confiaban en él, y no comprendían cómo se condenaba a la buena voluntad de ese señor. Por último le recordaron la falta de interés de los autores norteamericanos para estrenar en España, resultando para muchos directores y empresarios imposible la obtención de derechos. En resumen, el contrato tenía que ir a nombre de José Tamayo, porque era el que contaba con los avales ante Miller y la MCA. (Reiter, 1951: Carta a Tamayo, J.) Debió de captar José Tamayo perfectamente el contenido de las palabras de Mr. Reiter, puesto que le contestó sin ambages y solicitando el contrato a su nombre. Desconocemos la forma en que solucionó el conflicto con José López Rubio, pero el comediógrafo aceptó. Seguramente prefirió figurar como traductor de un texto tan importante a quedarse al margen del proyecto.

La imposición de la doble función diaria limitaba la duración del tiempo de representación, dejando los textos sujetos a cortes que ajustaran las comedias a las necesidades comerciales. Esta exigencia de la escena española de aquellos años quedó reflejada en la traducción de López Rubio, que llegó tarde a manos de los asesores de Miller, a los que no gustó el trabajo del traductor, preferentemente por la supresión de una escena importante, y porque afirmaban que el inglés de López Rubio era insuficiente. El problema subyacente fue que en las conversaciones preliminares hablaban de una traducción, no de una versión. Dado que eran unas fechas próximas a las navidades Arthur Miller no se encontraba en Nueva York, y por esta razón aún no se había reunido con sus asesores literarios desconociendo la opinión técnica de estos. Se colocó José Tamayo en una posición delicada: sin licencia de explotación concedida, un montaje ya prácticamente hecho, de una gran inversión económica, con el Teatro de la Comedia establecido el contrato y la fecha de estreno, unilateralmente fijada para el 10 de enero de 1952. La publicidad ya estaba elaborada y, en definitiva, nada concretado con el autor norteamericano. A sólo unos pocos días antes del estreno, recibió una carta de Reiter. Carta amenazante, pero cargada de razones en la que le culpaban a él exclusivamente de la situación. Miller se negaba a dar su autorización a una traducción llena de errores, los cuales -según Miller- hasta estorbaban el original, y por los cortes de la escena del restaurante. Reiter le informó que el día 24 de diciembre había estado almorzando con las gentes de MCA, explicándoles la situación en que se encontraban las cosas en Madrid, a lo que ellos contestaron que esa era la responsabilidad de José Tamayo y que de ninguna manera se sometían a 
presiones. Por fin el 28 de diciembre consiguieron mantener una entrevista con Arthur Miller en la se mostró muy enojado con todo lo sucedido, pero al final suavizó su posición y aceptó conceder el permiso, siempre y cuando se introdujeran los cambios que en hojas adjuntas a la carta les enviaba, aunque reiterando que la traducción era mala. (Reiter, 1951: Carta a Tamayo, J.) José Tamayo nada más recibir la carta de Reiter le envió un telegrama comunicándole que estaba dispuesto aceptar cualquier indicación que Miller hiciera sobre la traducción y, lo más importante, una carta con la garantía de que el montaje iba a ser supervisado por el Agregado Cultural de la Embajada Norteamericana, Mr. C. Titus y otra persona designada por él, que informarían en detalle a Mr. Miller.

Lo más relevante de todo este asunto fue el problema de la censura. A pocos días del estreno los más recalcitrantes repararon en que se producía un suicidio. En 1952 sobre un escenario español nadie se suicidaba. En la pantalla cinematográfica tampoco existía el suicidio, ni en las novelas radiofónicas. Pero también en 1952 las autoridades españolas no tuvieron valor de negar la autorización a una obra de teatro que era un suceso internacional, y de un autor originario de un país amigo, al que tanto necesitaban. El estreno de La muerte de un viajante dividió a la crítica entre el conservadurismo descalificador de Gonzalo Torrente Ballester y la postura inversa de Alfonso Sastre, Enrique Llovet etc., creando una gran polémica en la prensa. El público lleno durante mucho tiempo el Teatro de la Comedia.

El 20 de diciembre de 1956 José Tamayo estrenaba en el Teatro Español de Madrid, Las Brujas de Salem, en versión de Diego Hurtado, con un reparto encabezado por Francisco Rabal. Arthur Miller no puso ningún reparo a la solicitud de derechos de representación, a la versión, ni al montaje.

\section{BIBLIOGRAFÍA}

Gil Tovar, Francisco. (1952). Teatro de España en América. (C.L.V., Ed.) Heraclio Fournier (Vitoria) España. s/p.

Gómez Ramos, Marino. (1962). <Pequeña historia de grandes personajes. José Tamayo>. (Entrevista) Pueblo, Madrid. (20-VI. p. 26)

Matilla Jimeno, Alfredo. (1951-16-I) Nueva York. EEE. UU. Carta a Tamayo, J. Archivo de José Tamayo.

- (1951-6-VI)) San Juan, Puerto Rico. Carta a Tamayo, J. Archivo de José Tamayo.

ReIter, Frederick. (1951-25-X)) Nueva York, EE. UU. Carta a Tamayo, J. Archivo de José Tamayo.

- (1951-15-XI) Nueva York. EE. UU. Carta a Tamayo, J. Archivo de José Tamayo.

- (1951-28-XII) Nueva York, EE.UU. Carta a Tamayo, J. Archivo de José Tamayo.

Tamayo, José. (1944). <Por un teatro juvenil>. Cuadernos de Teatro (1), Granada. s/p. Recogido en: 50 AÑOS DE TEATRO: JOSÉ TAMAYO. (Ed. Andrés Peláez Martín). Ministerio de Cultura (1991), p. 123.

- (1950-26-X) Bogotá, Colombia. Carta a Matilla Jimeno, A. Archivo de José Tamayo.

- (1951-7-III) Medellín. Colombia. Carta a Barberá, M. Archivo de José Tamayo.

- (1951-4-IV) Barranquilla, Colombia. Carta a Matilla Jimeno, A. Archivo de José Tamayo.

- (1951-10-VI) San José, Costa Rica. Carta a Reyna de, G. Archivo de José Tamayo.

- (1951-14-VII) Miami, EE. UU. Carta a Reiter, F. Archivo de José Tamayo.

- (1951-5-XI) Granada. Carta a Reiter, F. Archivo de José Tamayo.

- (1953). <El teatro visto por un director $>$. TEATRO (5). pp. 33-38 


\title{
APÉNDICE DOCUMENTAL
}

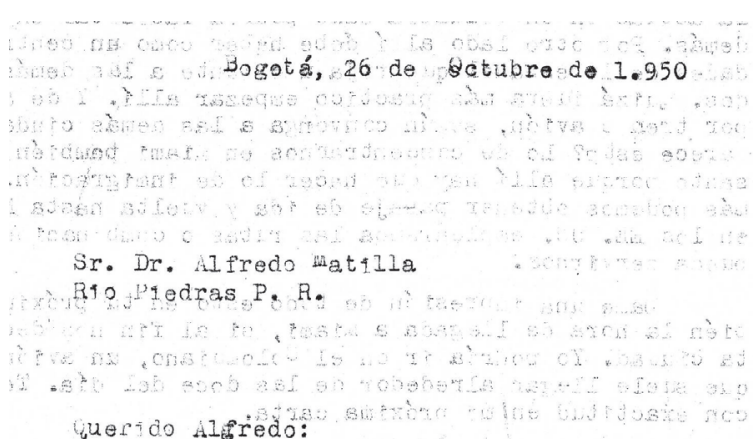 \\ He recjojdo a su debido tiempo tus dos cariño- \\ Sas cartas de 18 y 23 da octubre. \\ Q \\ 04 wo chucr yatenka yo techa metición de visado a la \\ -mbajada Ade cana. loy hé estado a entregar la solicitud. Los \\ trámptés sezún parece, no son otros sino los que anteriormente \\ se heclan: Poner unccable al consulado amerf cano en Madrid para \\ pedir informes. Hsto mismo ne hjoferon en la Habana el año pa- \\ sado. No croo que de ello se dedeuzca ninguna consecuencia des- \\ favorable. Yo no estoy en Palange, nunca he sido afjliado ni \\ be tenjo carnet, $Y$ eso de rollagro, pues ya sabrás que on cual- \\ quier organjsmo, en cualdiler oposición o trámite que aubjera \\ de darse en uspara 10 fundamtal era "ser del partido". No obs- \\ tante, que yo sepa, creo que estoy libre de tal cosa. Por tanto \\ espero tranquilo el resultado. We aen dicho que es cosa de una \\ semana. Lo demás que pe piden todo lo tengo y alguna cosa de \\ tipo local la he de sonsegujr sin ninguna dificultad en estos \\ días. De forma que si no hay contrariedad he de obtener mi visa- \\ do normalmente. sparte de estas gest ones busco la relación con \\ el agregado cultural que ha visto la Compañ́a y creo na de ayu- \\ darme. Te comunicaré lo que haya en segujda. \\ Ln todo lo derás estoy do acuerdo contigo. Fe- \\ chas, y detnás detalles. In Nueva York acostumoro ir al Ilotel \\ Alamac, en la calle 71 . He han tratado siempre muy bien. Manejan \\ el español con frecuencia y creo que lo pasarfamos estupendamente \\ Escribl a Blanco a la Argent1na. Le esplicaba \\ nuestros planes. wero no he tenido contestación de él. Te agra- \\ deceré que apenas liegue a Fuerto kqco le veas y que me escriba, \\ y aparte tu ne das la imoresión sobre sus planes respecto a nues- \\ tro viaje. \\ Cąsone tue ba escrito una carrixosisina carta \\ cuya copia te acompano nara tu conxiniento. Lime simetgopasejr- \\ le algo wás. \\ Lo de empezar por lisan o por Nueva lork es \\ aleo que debewos concretar. Hime que tuta gateresam
}

Carta de José Tamayo a Alfredo Matilla Jimeno. Bogotá (Colombia), 26-X-1950 

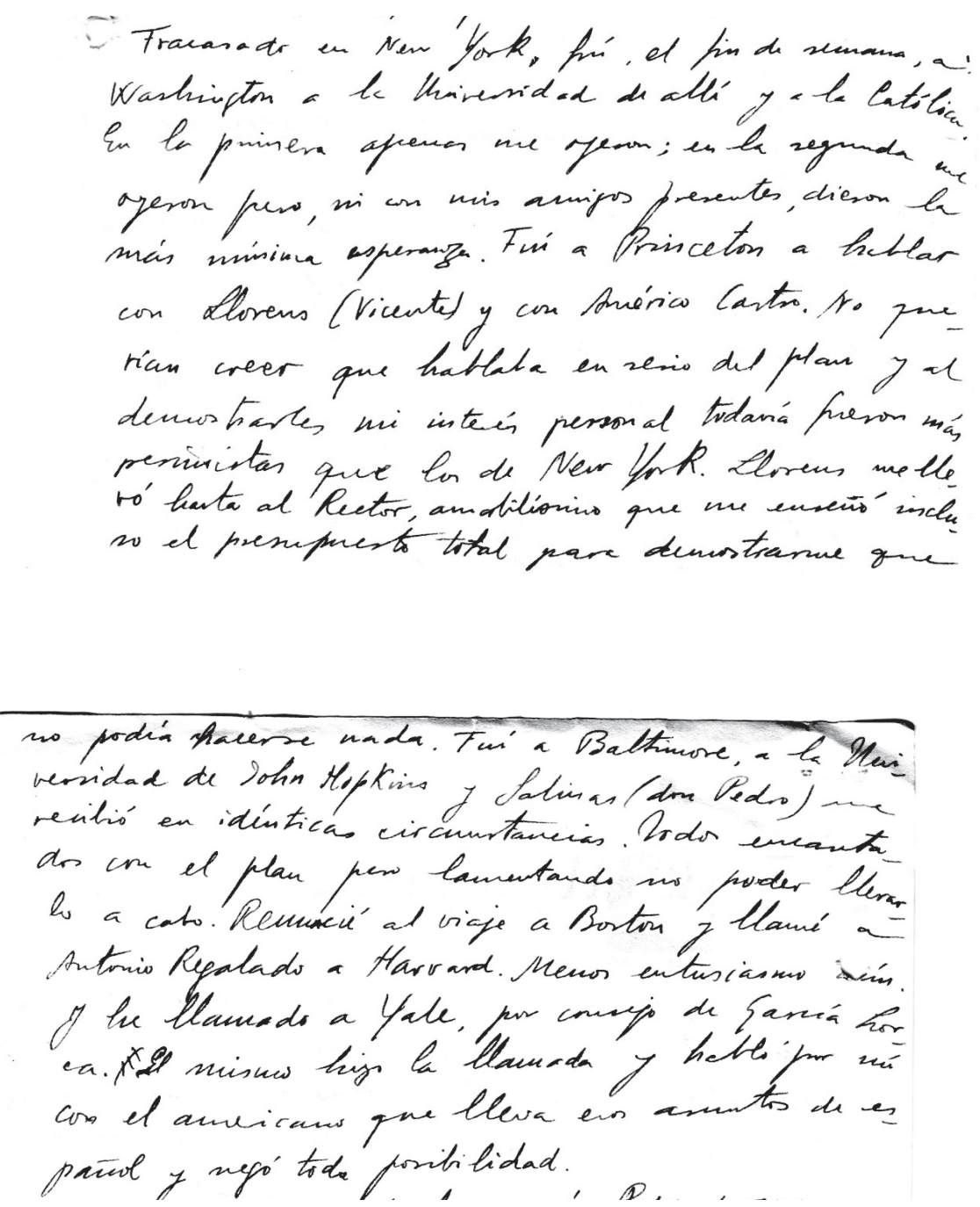

Transcripción

[...] Fracasado en New York, fui, el fin de semana, a Washington a la Universidad de allá y a la Católica. En la primera apenas me oyeron; en la segunda me oyeron pero, ni con mis amigos presentes, dieron la más mínima esperanza. Fui a Princeton a hablar con Llorens (Vicente) y con Américo Castro. No querían creer que hablaba en serio del plan y al demostrarles mi interés personal todavía fueron más pesimistas que los de New York. Llorens me llevó hasta el Rector, amabilísimo que me enseño incluso el presupuesto total para demostrarme que no podían hacer nada. Fui a Baltimore, a la Universidad de John Hopkins y Salinas (don Pedro) me recibió en idénticas circunstancias. Todos encantados con el plan pero lamentado no poder llevarlo a cabo. Renuncié al viaje a Boston y llamé a Antonio Regalado a Harvard. Menos entusiasmo aún. Y he llamado a Yale, por consejo de García Lorca. El mismo hizo la llamada y habló por mí con el americano que lleva esos asuntos de español y negó toda posibilidad [...]

Carta de Alfredo Matilla Jimeno a José Tamayo. Nueva York (EE.UU.), 16-I-1951 
Medelin 7 de narzo de 1.951

Sr. Hon manuel Barberé

Sociedad Arizentina de Autores

Buenos "hitres. r.h.

huy señor m4o:

Tengo el gusto de der is rwe a Vd. para exponerle el asunto sqgusente:

He tentdo ocasión de $v \in r$ en Bogotá, ofrecida por

la Compaña Argent ina de Francasco Petrone, la adra rable versión que Va. tiene necha de la obra de sithur Miler "La Muerte del Viajante", obra por la que yo estoy interesado desdo nace mucho t1empo, y cuyus gestiones de concesión de exclusiva para Espara nabla encomendado recientemente a un ang go mo en Nueva York. Pero al conocer su traducción he pensado que wucro was práctico serfa ol conseguir la obra por mediación de Va. y orrecerla en España, sg ello fuera posiblo, según la versión castellana que acabo de conocer.

Hi Compañ del 49 y su regreso a España está fijado para finales de este m smo año. He es interesant 1 simo llevar a ispaña estas novedades del taatro amertcano $y$ entre ellas, croo la was sensacional "La Nuerte del Vyajante". In Lispaa se nos aguarda con el wayor interés y nuestra ruta na de comprender actuaciones en Madrid, Barcelona, y tocias las cqucades 9 portantes, not 4 vo que vendrfa a asegurar aín was el éxto indascut ble de la obra, durante cientos de representac"ones.

por todo ello, yo ruebo a Va. que we dontesto st muede contar con el autor del orqginal, Arthur lilller, para que sea esta versión la que en exclusiva pueda darso en toda

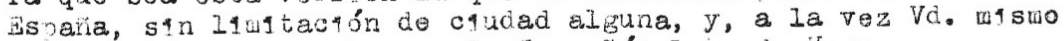
pueda nacer otro tanto con la Compañfa Lope de Vega.

Yo no tengo el wenor antececiente de que en España se haye representado, pero convione nacer esta d4ligencia con

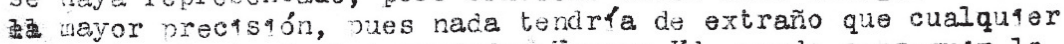
traductor la tuvqera concedida, Apenas Vd. pueda consegur la preciada autor zación touar amos las medidas necesarıas para que el estreno fuera reservado a nuestra Compa da, adelantando la gayor visilancia para que nt en los Teatros de Camara pravados pudaera representerse. Constdero esta obra, baen lanzada y

Carta de José Tamayo a Manuel Barberá. Medellín (Colombia), 7-III-1951. 
ฟิarranqu1118, 4 de Abr1] de 1.952

Sx. Don Alrodo Hat11la.

Univerosaded do puarts Bico.

Rlos1odrase-

Chortao Alfroco: Ilovo aloun t1eapo alsn tener tus acraiabios noctias. sl

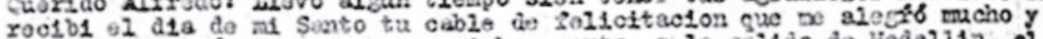

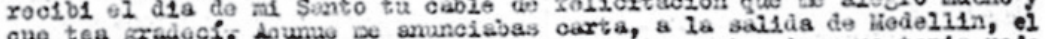

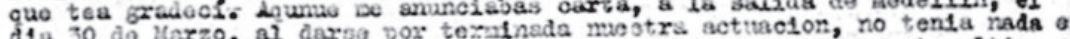

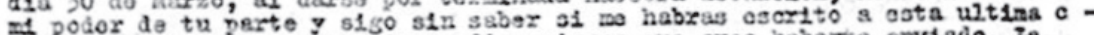

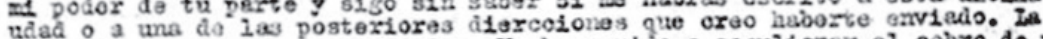

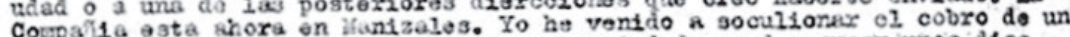

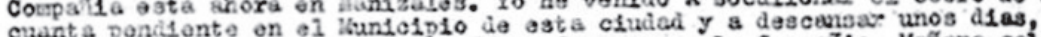
porqua astabs aleo azotaio. Ti vaelvo de mevo a la Corpsîla. Kañens saigo



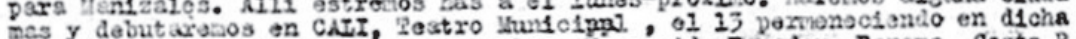

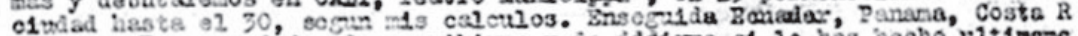

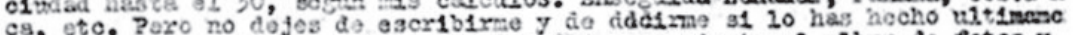
es, etc. ? las oue to pedis lo $I_{0}$ tindversidad $\mathrm{y}$ Puerto Rlco, que to acradocro rucho.

V1-on Bosota, representada por una Cospaüsa Argontina quo acaba de do-

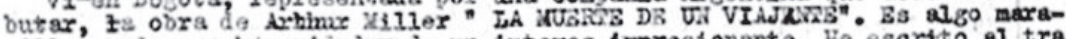
v1110so, do una hinninisa $y$ de un interes 1mpresionanto. Ho escrito al tra ductor, un tal :Tamtei Burberá, espaijol, dondolliato en irgontina, en solloftud do la excluatva pura Bspuria. Serk a una novedad interasante para $x$

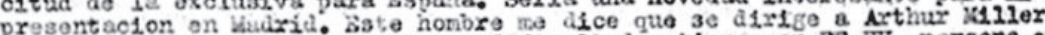
presontacion on duri o su

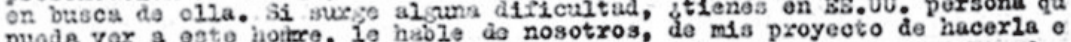
dspaña con $10 s$ neccison honoros, $y$, on $11 \mathrm{n}$, de perruadirlo para que nos do Io oxclugivo de estreno y raprosontacion? Creo que conseguir tai sunto

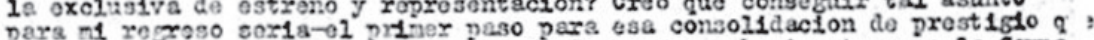

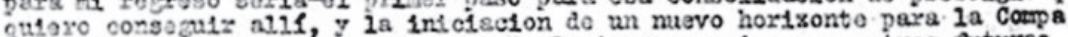
1 . Por clerto gus ya tongo acoptada le 1ncorporacion a mostras cuturne - 1 in ratog J jovenos?. B3 adepas persona que por haber tentdo escssos alos de


tral proposion. Bstivo de prisor actor on ol Bspaloi y ol Kurla Guerroro cu atro \& c1noo tanporedas. Bsta hac1endo "c1ne" unos sols afos aosuldos. Su rogre so al Teatro colncidirla con ol de nuestra presentiolon on Deslarid. Coso poras ostoy plonarente dec1d10 s nonor on prict1ca ol plas qua hesos hablaio anchas vocos: rounir nua Cospoffis guo puede sor ura rordedora oxprosion do 103 najoras valoros que poses of toetro español, on todos 108 aspectos.-

to dejes de escristrve. S1 reosbo eluna notcla tiya a mi rogroso a la Cormaña to 10 cominlcaro onsegulda. S1 no ruera as es qu ootoy asperando tus noavadedas.-

Todo nos marcha my bion. Vareros cono reacelonan 103 poouoños palses

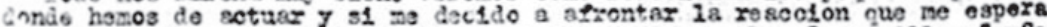

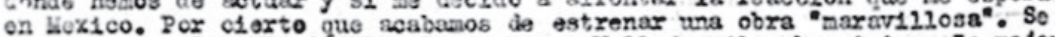

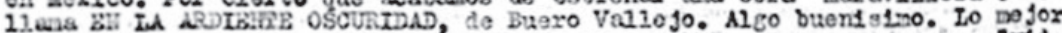
do toilo 10 cue 11 cramos. Ion porsonnjos son olegos, monos uno quo os "vido: ta". Pucdo somos my uili en Itex1co. Si deoldo tal cosa no gustria cambia 
Me encantaría que consiguieras en Nueva York lo que yo no conseguí: una entrevista con Arthur Miller. De momento no se me ocurre quién puede orientarte, en Nueva York, en casos estrictamente teatrales. ¿Por que no tratas de conseguir una entrevista con José Ferrer a quien puedes anunciarte como el Director de tu Compañía que estuvo en Puerto Rico? El te podría orientar muy bien.

Blanco me dice que le han escrito Santamarta y Avelino, que al parecer quieren venir aquí con sus parejas respectivas para unirse a Esteban de $\mathrm{Pa}-$ blos a hacer algo de radio. Me parece que los pobres no saben dónde se van a meter.

Blanco te "perdona" y te envía un abrazo. Cerraré esta carta para que te llegue pronto. El comentario que me pides sobre el paso de la Compañía por América te lo hago en esta semana sin falta y te lo mando en segulda.

Y bast por hoy. No me dejes tanto tiempo sin cartas y cuéntame más cosas. Todo lo tuyo me interesa extraordinariamente. A Cecilia y Alonso (el futuro representante) un abrazo fuerte y para tí muchos más con el ceriño entrañable de

AM: sb

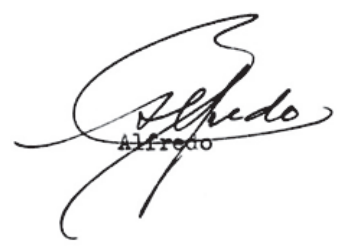

Carta de Alfredo Matilla Jimeno a José Tamayo. San Juan (Puerto Rico), 6-VI-1951.

La compañfa terwinurá ofreralmente para ol 20 de Jun4o. Los artistas marcharan a La Habana, on aván, para salar el 25 en un parco español, nacsa Espuña. Yo marcharé a los jij. UU•, porque voy a permanecer en Nueva Yorik, y otras cqudades, durante un mes. Tengo entrovastas preparadas con arthur M4ller, con P4scator y uno de sus mejores colaboradores, el Dr. Colin, ango nuestro. Tamdén con José Ferrer, al que conocf personalmente en Puerto Raco, y que me va a servar de "antroductor" en ol amb ente teatral neoyorquano.

Qua zá, antes de na regreso, marcharé a Tnglaterra, para as4stır, durante los Festivales Br4tán cos, a las representac^ones teatrales de caracter anternacional que han de celebrarse entalmburgo $y$ en Straford on Avon.

DHsoués vasıtaré Parıs, ¿Cree vid. que s* MARTA CAJAFis, la actraz española, consaderada como una de las mejores anterprotes del teatro francés, escuviese dispuesta a 1 ncorporarse a w*s planes, exissirfa alguna dificultad de tapo polftaco para su rogreso $\checkmark$ libre actuacán en ispaña?

Carta de José Tamayo a Guillermo de Reyna. San José (Costa Rica) 10-VI-1951. 




Mlami Beach, Florida, 14 de Jul10 de 1.951

Mr. Frederick J. Reiter

Representante de la Socieded General de Autores do Ispaña

124 Tast 71 st. Street.

Ner York, $2 I$ N. Y

.

Muy señor mio:

Labo de recibir, reexpedzda desde La Habana, su apreciable carta de focha 9 de Jul1o, que conteito en seguida.

Le aradezco muchísimo su buena disposición para inlciar las gestiones con los representantes de Artaur Miller, líCA. para conocer las condiciones en que se me podría autorizar en exclusiva para Bspaña, la obra "La kuerte de in Viajante", (The Death of Salesman).

Istoy sepuro qu 1 legaremos a un acuerdo con ellos: Io mas iruportante, mientras 11 ego a Nom York, quo será para el día 26 de este mes, es que Va. naga la petición para evitar que sea concedida a otro cualquier solicitante, y adernás que logre Vd, de ellos jas mínimas condiciones andeque estarían dispuesto a concederme la autorización. Deben tener en cuanta que lia Compaña Lopo de $V_{e g a}$ es una Compañía de prest1g10, que la obra va a ser traducja por uno de los mejores autores españoles, quijá Juan Ignacio Luca de Tena, director, propietario del Diario A.B.o., y que va a ser estrenada en un Teatro de Madrid y reoresentada on casi toda Rspaña por la misma Comparía. Todo ello son una sorie de garantias que preden facilitar unas condiciones "posiblas".

En cuanto a parantizar el cobro de los derecnos $y$ el carbio de moneda, etc. etc. creo quo podrems llegar un acuel do. Ignoro que disoos1ciones Iegales hay en Ispaña sobre ofte n asunto. Usted estará enterado, poro por mi parte ofrezco cuantas. facilidades sea posibles.

de rosolverse facilmente.

Tengo la seguridad de que con su ayuda toda ha

Quizá el próximo lunes o martes, sepresentará a. visitarle, en mi nombre la Srta. Consuelo vazquez que acaba de salir hoy en dirección a Nery York. Io he oncotaendado que lo visite con el misto fin. Todavía yo no había recibido su carta. Por tanto,dígale que estanos ra de acuerdo Vd. y yo, e informele unicamente de cualouler novedad que haya sobre ol particular.

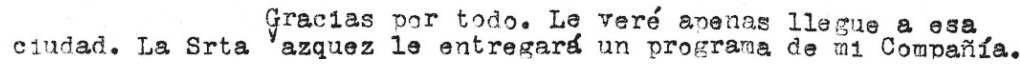

Carta de José Tamayo a F. Reiter. Miami (EE.UU.), 14-VII-1951. 


\section{SF, gIEDAD GENERAI DE AUTORES DE ESPAT}



Carta de F. Reiter a José Tamayo. Nueva York (EE.UU.), 25-10-1951. 
Wir. Erederick Reiter 124 East 71st. Street New York $\angle \mathcal{L}-\mathrm{N}, \mathrm{Y}$

Wi estimado amigo:

He Ilegato a mi poder, por medio deI Sr. Iizarraga, su grata carta, fe fecha 2.5 de 0etubro, que cebifó aruzarse con la mía última, enviada desde Madrid en los últimos dís ce mes.

oe af and Teitero que deseo formalizar contrato en firme pare la obra de Arthur tiiller, THE JEATH OF A SAIESMAN, cuyo original traducido por JOSE IOPES RUBIO, le poj a enviar de un dia a otro.

. El contrato debe ex tenderse a nombre del autor que hace la traducción, (no a mi nomore) y en las condiciones que nosotros tenemos habla as. Yo acompanaré a Va. un cheque de US\$300.00 como anticipo para $\in I S_{Y}$. Miller, que será escentado a razón de 15,000.00 Pts, (que viere \& ser la cotización en pesetas en el mercado libre. Estas pesetas serán descontadas al Sr. Miller de 10 s primeros ingresos en pesetas quo produacan sus derechos en Espana. El porcentaje del Sx. Miller sera, según hablamos, del 6\% del ingreso de taguila. Cuando la obra se represente en países fuera de ispafa, Ios derechos deI Sr. Miller serán abonados en las divisas corresponcientes a cada país.

Entre el Sr. Iópez Rubio $y$ jo, se hará un contrato, ce forma que yo cuente oon la exclusiva de la obra para representar en Espana,

Ia cantidad anteriormente indicada de US\$300.00, será enviaca a $V$. cuan o 3 lga hacia Nueva York el original traducido, y acienás los US, 50.00 por formazización de contrato y los que $\mathrm{V}$. me indicaba para atender pequeños gastos. 0 sea, no hay inconveniente alguno para dejar satisfechos, por nuestra parte, los gastos que exte asunto lleva consigo, a nas el antioiro.

In cuanto a THE MOON IS BIUE, estoy muy interesaco. Como la traducción va a ser hecha tambiér por Iópez fuoio, habrá que

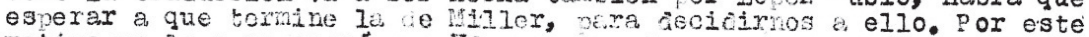
motivo yo lo agra ecers que $\nabla$ a. me conceda unas denañs ae espera. Io mas seguro es que tanión 25 joliojtemos, g no hore inconveriente alguno on que $\$ 0$ aboner 205 US\& 300.00 e enticto, eto. Sin embargo, hasta tarto, rocure dejar el asurto en ms,erso, pues mi opinión es yo llegaremos a un acuerdo.

Carta de José Tamayo a R. Reiter. Granada, 5-XI-1951. 


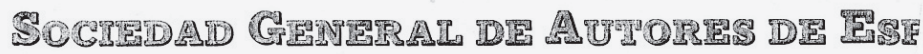

TEL. REGENT 7-6617

\section{U. S. REPRESENTATIVE}

el 15 de loviombre, 1951
124 EAST 71 ST STREET NEW YORK 21, N. Y.

Senor Jose Tamayo Rivas

Santa Paula, 21

Granada, Spain

Mi estimado amigo:

Recibi su carta con fecha del 5 del actual y me alegro saber que la traducion de DEATH OF A SALESMAI estd ya hecha y liegard en mis manos dentro de poco.

He hablado con MCA y estamos al tanto de la lilegada,

asi de la traducion como del cheque mencionado.

Tambion he discutido el asunto con mi abogado y es en consecuencia de estes conversaciones que hoy le escribo.

Va. me dice que el contreto deberia extendenser a nombre del autor traductor, $\mathrm{y}$ es este detalle que no nos gusta, sea en el interes de Vd. mismo como tambien bajo el punto de vista de MCA. ElIos conocen a Vd. $\mathrm{y}$, en base de cunto les di.je sobre su persona y nombre como director de lajcompania Lope de Vega, les gusta tratar con Vd. Desconocen al Sr. Lopes Rubio, y estoy seguro que crearia dificultades ohora pedir que el contrato dea extendido a nombre de el.

Por el otro lado, seria dificil para el Sr. Lopes Rubio de tomarse las responsabilidades que Vd. se tomerd on base al contrato, o sea representer la obra. en Madrid dentro de un ano, garantizar el pago de las regalias, etc.

Por esta razon le someto mi sugestion de hacer el contrato en nombre suyo, ya en vista de todo eso y tambion para no hacerse dependiente de la buena voluntad del Sr.Lopes Rubio que, si se extenderia el contrato a nombre de el, seria el dueño de la obra para Espeña. Tambien hay que considerar que, una vez firmado y cumplido el contrato con Vd., ya serd tanto nds facil on lo futuro de conseguir otras obras para Vd., nientras como sabe Va. resulto casi imposible a otros avtores y directores de España de obtener las obras que desearon obtener.

Por todas estas razones le ruego sirvase ponerme unacarta aerea lo antes posible autorizandome de preparer el contrato a nombre de Vd.; Iuego, tanpronto que llegue la traducion y el cheque, hare firmar el contrato por MCA y por Va.

En cuanto a THE MOON IS BLUT ya se que otros se han interesado para los derechos para España y America del Sur, pero por el momento nos tienen reservando la obra aunque no puedo garantizar por cuanto tiempo. Sin ma para hoy le saludo su sincero amigo

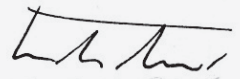

Carta de F. Reiter a José Tamayo. Nueva York (EE.UU.), 15-XI-1951. 


\section{SOCHEDD GENERA DE AUTORES DE ESPANA}

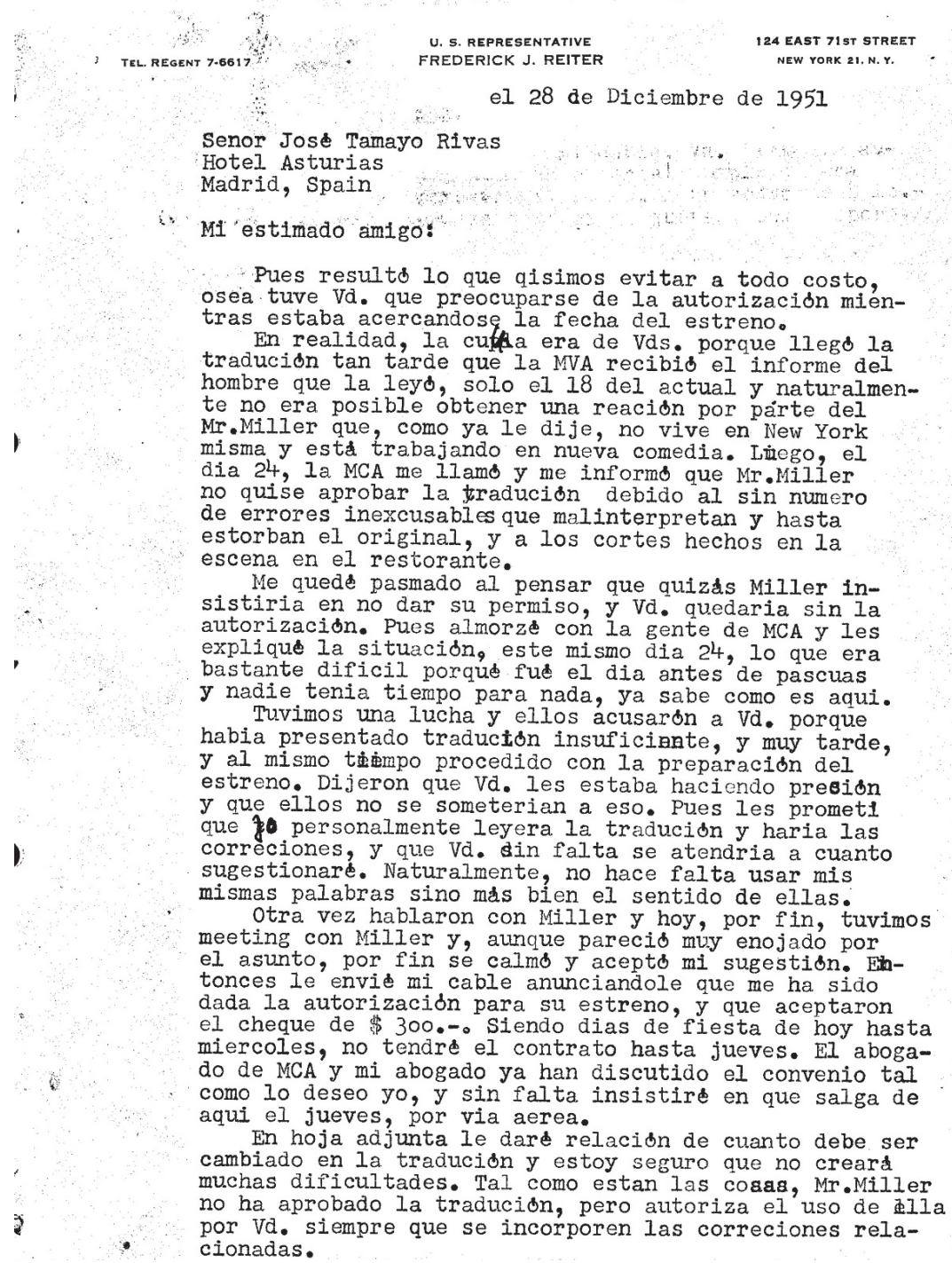

Carta de F. Reiter a José Tamayo. Nueva York (EE.UU), 28-XII-1951. 